\title{
Quality of Life among Children with Juvenile Rheumatoid Arthritis
}

Faransa Ali Ahmed: Lecturer of Pediatric Nursing, Faculty of Nursing, Assiut University, Egypt

Safaa Rashad Mahmoud: Assistant. Prof. of Community health Nursing Faculty of Nursing, Assiut University, Egypt

Shimaa Abd-elrehem: Lecture of Community health Nursing, Faculty of Nursing, Assiut University, Egypt

Alameldin Abdallah: Assisstant Prof of Pediatric

Faculty of Medicine, Assiut University, Egypt

\begin{abstract}
Background: Chronic rheumatologic disease in children is juvenile rheumatoid arthritis, yet little is known about their health-related quality of life .Aim of the study was to describe Health Related Quality of Life in self-reports of children with juvenile rheumatoid arthritis. Subjects and Method: descriptive research design was used in this study. A convenience sampling technique was used for 100 children aged from8 to 18 years who had been attending to rheumatology unit and rheumatology outpatient clinic at Assiut University Children Hospital. Results: There was a statistically significant impaired in pain and hurt, daily activities, treatment, worry and communication among children with juvenile rheumatoid arthritis. Conclusion: children with juvenile rheumatoid arthritis have lower health-related quality of life. Recommendation: The study recommended that health promotion program for children with juvenile rheumatoid arthritis, and their family members are needed. Nurses, physicians, parents and teachers must be informed of the risk for impaired health-related quality of life among juvenile rheumatoid arthritis children to promote interventions that must improve health outcomes.
\end{abstract}

Keywords: Juvenile, Rheumatoid, Arthritis, Quality of Life, 


\section{Tanta Scientific Nursing Journal}

\section{Introduction}

Juvenile idiopathic arthritis (JIA) known as juvenile rheumatoid arthritis (JRA), is the highest public type of arthritis in childhood. Juvenile means start before age 16, idiopathic means a state with unknown cause, and arthritis is the inflammation of the synovium of a joint. JRA is an autoimmune, non-infective, inflammatory joint disease of more than 6 weeks duration in children less than 16 years of age $e^{(1)}$.

Quality Of Life (QOL) is a broad concept with multiple dimensions (domains) that contain the personal sense of physical and mental well-being. A more definite use of the term is health related (QOL) which emphases on the variations in physical and mental health domains that can cause diseases $^{(2)}$.JRA usually happens in children from the ages of 7 to 12 , but it may happen in adolescents as old as 15 years of age, as well as in infants. It is a subcategory of arthritis seen in pediatric, which may be temporary and self-limited or chronic. JRA affects approximately 1 in 1,000 children yearly, and about 1 in 10,000 having risky illnesses $^{(3)}$.

The causes are unknown, and the genetic factor is difficult, constructing strong differences between the different subtypes hard. A novel nomenclature, JRA, is presence progressively used to offer improved explanation of subgroups ${ }^{(4)}$.

Symptoms of JRA are mainly non-specific starting, and contain lethargy, diminution physical activity, and decrease appetite. The paramount sign, mainly in young children, may be limping. Children may also been quite ill, giving with flu-like symptoms that continue. The cardinal clinical feature is insistent swelling of the affected joint(s), which usually contain the knee, ankle, wrist and small joints of the hands and feet ${ }^{(5)}$.

During examination Swelling may be hard to observe, mainly for joints such as those of the spine, sacroiliac joints, shoulder, hip and jaw, so ultrasound or Magnetic Resonance Imaging (MRI) are very suitable ${ }^{(6)}$.

Pain is a vital symptom. Morning stiffness that recovers future in the day is a common sign (this implies inflammatory type joint pain versus mechanical type joint pain). Chronic arthritis may result in swilling due to synovial proliferation and congealing, and specific soft tissue swelling may appear at children ${ }^{(7)}$.

Diagnosis of JRA is dependent on the physical examination findings and taking the history. When physical findings do not sure arthritis, other investigation is necessary. 


\section{Tanta Scientific Nursing Journal}

Laboratory investigations contain inflammatory markers: erythrocyte sedimentation rate, complete blood count and metabolic panel must be done ${ }^{(8)}$.

Treatment techniques for JRA through pharmacologic therapy with no steroidal anti-inflammatory drugs, antirheumatic medications, or intra-articular and oral corticosteroids, psychosocial mediations, actions to advance school practices (eg, academic or school counseling), enhanced nutrition, physical therapy and occupational therapy. Synovectomy, osteotomy, arthrodesis, hip and knee replacement may be used, but surgical intervention now is limited $^{(9)}$.

Nursing management for children with pain in their hands and wrists, utensils and devices must be lightweight with large handles as well as other equipments (such as angled knives, strap-on utensils, jar and bottle openers, turning handles, door knob extensions, etc.) given to make the duty easier, less painful and more enjoyable. Children with neck stiffness can be used tilted glasses ${ }^{(\mathbf{1 0})}$. Nursing education can be provided about good eating habits that help control bone loss caused by inactivity and drug side effects. Nursing role during occupational therapists provide a numerous of plans to assist children with JRA in accomplishment self-care responsibilities ${ }^{(\mathbf{1 1})}$.

Varni et al. ${ }^{(\mathbf{1 2})}$ who establishes the Rheumatology Module to distance a very wide age range for child self-report and an even wider age range when involving parents-report. The PedsQL Rheumatology Module 3.0 modified a validated scale of many domains of HRQOL definitely vital to JRA children by James and Varni ${ }^{(13)}$. Treatment delaying among JRA children and adolescents, or severe case mainly grows joint deformities of the hand and fingers. Later hand function is lost and practically difficult to improve, moreover the side effects of corticosteroids that decrease growth. Other musculoskeletal subjects may include joint contractures, muscle weakness or muscle loss, and osteoporosis $^{(\mathbf{1 4})}$.

Numerous studies were discuss healthrelated quality of life for adults with rheumatoid arthritis while limited number of study presented for children, so some researches were wanted to stress on the relationship between pain of JRA children and their health-related quality of life due to the highly effect of pain and deterioration in joint working on the children abilities that 


\section{Tanta Scientific Nursing Journal}

can be reflect on children's performance at school and their relations with peers in or out-school that can be cause social isolation and disturbance in children physical, social and emotional developments beside physical deformity $^{(10)}$.

\section{Aim of the study}

Investigate quality of Life among children with juvenile rheumatoid arthritis

Research Question : What's the Quality of life among children with Juvenile Rheumatoid Arthritis

\section{Subjects and Method:}

Research design : Descriptive research design was used in the study.

Setting : The study was carried out at rheumatology unit and rheumatology outpatient clinic of Assiut University Children Hospital.

\section{Subjects:}

Convenience sampling technique was used in the current study. The total number of participants was 100 children diagnosed with juvenile idiopathic arthritis at least 6 months prior to the study, didn't have any other chronic diseases and able to communicate plus 100 healthy peers matched in age \& sex were aged from 8 to 18 years to compare the effect of the juvenile idiopathic arthritis disease on the children health related quality of life.

\section{Tools of data collection}

Two tools were used to accomplish this study:-

Tool (1): Interview structure that developed by the researchers, it includes two parts: -

Part I: Children's demographic characteristics such as age, sex, education, residence.

Part II: Medical history of the disease, its onset, duration, treatment, if have any complication

Tool (II): A pediatric QOL (PedsQL ${ }^{\mathrm{TM}} 3.0$ ) rheumatology Module which developed by Varni et al. 2002 $^{(\mathbf{1 2})}$ it is a 5-point likert scale from 0 (never) to 4 (almost always), used as the measure of healthrelated QOL for rheumatoid children. This scale is composed of 22 items and includes 5 dimensions that measure pain/hurt (4 items; 1 - I ache or hurt in my joints and/or muscles, 2-I hurt a lot, 3-I have trouble sleeping because of pain or aching in my joints and/or muscles and 4-I feel stiff in the morning or when I sit too long), daily activities (5 items; 1- It is hard to turn on water faucets, 2-It is hard to turn door handles, 3-I have trouble eating with a fork 


\section{Tanta Scientific Nursing Journal}

and knife, 4-It is hard to write or draw with a pen and pencil and5. I have trouble carrying my school books), treatment (7 items; 1. My medicines make me feel sick, 2-My physical therapy or daily exercise hurts, 3-It is hard to be responsible for my medicines or physical therapy, 4-It is hard to manage my illness, 5-I get scared when I have to have blood tests, 6-I get scared about having needle sticks/shotsand 7-I get scared when I have to go to the doctor), worry (3 items; 1. I worry about the side effects from medicines, 2-I worry about whether or not my medicines are working and 3. I worry about my illness), and communication (3 items; 1 - It is hard for me to tell the doctors and nurses how I feel, 2-It is hard for me to ask the doctors and nurses questions and3. It is hard for me to explain my illness to other people). Recall period for items respondent's answers address the past month. The reliability was measured for internal consistency using Cronbach alpha coefficient method $\alpha=0.83$ for children, which indicated high degree of reliability. The validity was measured by five experts in the field of pediatric nursing and rheumatology for face and content validity

\section{Scoring system:}

For ease of interpretability, raw scores for each item are reversed scored and linearly transformed to a 0-100 scale as follows: $0=100,1=75,2=50,3=25,4=0$ with a higher score indicating a better HRQL (i.e. Higher scores indicate lower problems or fewer symptoms).

Score system of children's quality of life distributed as the following:

Poor quality of life: $<50 \%$

Fair quality of life: from 50 to $-<75 \%$

Good quality of life: $75 \%$ and more.

\section{Method}

1- An official permission was taken from the Assiut University Children Hospital administrators and the manager of the outpatient clinics, and from the head nurse of the rheumatoid clinic to gain their cooperation.

\section{2- Ethical considerations:}

- Verbal consent was obtained from the study subjects after explanation of the purposes of the study

- Confidentiality were assured to the study subjects

- The study subjects had the right to withdrawn from this study at any time 


\section{Tanta Scientific Nursing Journal}

and this should be respected and assured

-Confidentiality of any obtained information was ensured.

-The study questionnaire doesn't entail any harmful effects on participated children.

3- All Children coming to the rheumatoid out-patient clinic for follow up or admitted at rheumatoid unit for treatment who fit the criteria were included in the study..

4-Tools (tool I,II) were tested for content validity by a jury of five experts in the field of Rheumatoid out-patient clinic at Assiut University Children Hospital

5- The pilot study: It was carried out on $10 \%$ of the study sample. also served to test the feasibility, clarity and applicability of the tool. Also, the pilot helped the researchers to estimate the time needed to collect the data, feasibility and the applicability and necessary modifications were done accordingly..

6- Each child were interviewed to complete the questionnaire. Researchers faced the clients, asked them the questions in Arabic and recorded their answers in the interviewing questionnaire sheet. The interview was carried out in the waiting area at the rheumatoid outpatient clinic and it took about 30 minutes for each one.

7-All The Rheumatoid out-patient clinic at Assiut University Children Hospital is working at Monday Wednesday 9am to $1 \mathrm{pm}$. The total number of cases coming to the clinic for each day is from 3 to 4 children for follow up. The total number was 100 children (16 children from the rheumatoid unit and 84children from the out-patient clinic)

8-Data were recruited within a period of 6 months from January and December 2016.

\section{Statistical Analysis:}

Data entry and statistical analysis were done using SPSS 20.0 statistical software package. Descriptive statistics (number, percentage, mean and standard deviation) were done. Chi-square test was used to compare between qualitative variables. Comparison between continuous variables by t-test and ANOVA test spearman correlation was done to measure correlation between child scores regarding JRA.

\section{Results}

Table (1) shows comparison between children with JRA and healthy children as regard personal data. It was found that mean 
age of rheumatoid children were 13 years, and mean age of healthy children were 13.6. According to their education, it was clear that $37 \%$ of case children have primary education, while $27 \%$ of healthy children have secondary education.

Table (2) shows relationship between levels of quality of life for children with JRA and healthy children. Highly statistically significant difference was found between quality of life levels of children with JRA and healthy children. Majority (71\%) of children with JRA have poor level of quality of life while, $10 \%$ of healthy children have poor level. More than half (60\%) of healthy children have good level of quality of life while, $7 \%$ of children with JRA have this level of quality of life.

Table (3) shows relation between total scores and main scores of quality of life domains for children with JRA and healthy children reports. Highly statistically significant difference was found between total scores and main scores of quality of life domains for children with JRA and healthy children.

Table (4) shows correlation between mean score of the children with JRA and healthy children reports regarding to quality of life domains. Highly statistically significant difference was found between mean score of the children with JRA and healthy children reports for all quality of life domains.

Table (5)shows comparison between quality of life levels and personal data of children. Highly statistically significant difference was found between quality of life levels of children with JRA and their education, gender and residence. Highly statistically significant difference was found between quality of life levels of healthy children and their age, and education.

Table (6) shows correlation between quality of life domains in the studied group. Highly statistically significant difference was found between all domains of quality of life in the studied group. 
Tanta Scientific Nursing Journal

Table1:- Percentage distribution of studied children regards socio-personal characteristic

\begin{tabular}{|c|c|c|c|c|c|}
\hline \multirow{2}{*}{$\begin{array}{l}\text { Socio-personal } \\
\text { characteristic }\end{array}$} & \multicolumn{2}{|c|}{$\begin{array}{l}\text { Children with JRA } \\
\qquad(\mathrm{n}=100)\end{array}$} & \multicolumn{2}{|c|}{ Healthy Children $(n=100)$} & \multirow[t]{2}{*}{ P. value } \\
\hline & No. & $\%$ & No. & $\%$ & \\
\hline Age (M+SD) & \multicolumn{2}{|c|}{$13 \pm 1.78$} & \multicolumn{2}{|c|}{$13.6 \pm 1.82$} & $0.019 *$ \\
\hline \multicolumn{6}{|l|}{ Gender } \\
\hline Males & 34 & 34 & 34 & 34 & \multirow{2}{*}{1.000} \\
\hline Females & 66 & 66 & 66 & 66 & \\
\hline \multicolumn{6}{|l|}{ Level of education } \\
\hline Non educated & 19 & 19 & 9 & 9 & \multirow{4}{*}{$0.03^{*}$} \\
\hline Primary & 37 & 37 & 27 & 27 & \\
\hline Preparatory & 23 & 23 & 31 & 31 & \\
\hline Secondary & 21 & 21 & 33 & 33 & \\
\hline \multicolumn{6}{|l|}{ Residence } \\
\hline Rural & 36 & 36 & 54 & 54 & \multirow{2}{*}{$0.016^{*}$} \\
\hline Urban & 64 & 64 & 46 & 46 & \\
\hline Mothers' age (M+SD) & \multicolumn{2}{|c|}{$42.11 \pm 9.56$} & \multicolumn{2}{|c|}{$39 \pm 4.45$} & $0.004 * *$ \\
\hline \multicolumn{6}{|l|}{ Mothers' jobs } \\
\hline Worked & 28 & 28 & 36 & 36 & \multirow{2}{*}{0.289} \\
\hline Housewife & 72 & 72 & 64 & 64 & \\
\hline \multicolumn{6}{|l|}{ Mothers' education } \\
\hline Educated & 60 & 60 & 65 & 65 & \multirow{2}{*}{0.560} \\
\hline Non educated & 40 & 40 & 35 & 35 & \\
\hline
\end{tabular}

* Statistically significant difference $(\mathbf{p}<0.05), * *$ Highly statistically significant difference $(\mathbf{p}<\mathbf{0 . 0 1})$. 
Table (2):- Relationship between quality of life levels of children with JRA and healthy children

\begin{tabular}{|c|c|c|c|c|c|}
\hline & \multicolumn{5}{|c|}{ Children } \\
\hline & \multicolumn{2}{|c|}{$\begin{array}{c}\text { Children with JRA } \\
(n=100)\end{array}$} & \multicolumn{2}{|c|}{$\begin{array}{c}\text { Healthy Children } \\
\quad(n=100)\end{array}$} & \multirow[t]{2}{*}{ P. value } \\
\hline & No & $\%$ & No & $\%$ & \\
\hline \multicolumn{6}{|l|}{$\begin{array}{l}\text { Levels of Quality } \\
\text { of life }\end{array}$} \\
\hline Poor & 71 & 71 & 10 & 10 & \multirow{3}{*}{$<0.001 * *$} \\
\hline Faire & 22 & 22 & 30 & 30 & \\
\hline Good & 7 & 7 & 60 & 60 & \\
\hline
\end{tabular}

*** Highly statistically significant difference $(\mathbf{p}<0.01)$.

Table 3:- Relation between total scores and main scores of quality of life domains as regard (Children with JRA, Healthy Children)

\begin{tabular}{|l|c|c|c|c|}
\hline & \multirow{2}{*}{$\begin{array}{c}\text { Total } \\
\text { score }\end{array}$} & $\begin{array}{c}\text { Children with } \\
\text { JRA (n=100) }\end{array}$ & $\begin{array}{c}\text { Healthy } \\
\text { Children } \\
\text { (n=100) }\end{array}$ & P. value \\
\hline Pain and Hurt & 16 & $3.56 \pm 2.82$ & $13.23 \pm 2.55$ & $<0.001^{* *}$ \\
\hline Daily Activities & 20 & $4.47 \pm 3.76$ & $17.53 \pm 3.33$ & $<0.001^{* *}$ \\
\hline Treatment & 28 & $6.47 \pm 5.84$ & $23.97 \pm 5.07$ & $<0.001^{* *}$ \\
\hline Worry & 12 & $2.76 \pm 2.43$ & $10.1 \pm 2.31$ & $<0.001^{* *}$ \\
\hline Communication & 12 & $3.07 \pm 2.53$ & $10.08 \pm 2.62$ & $<0.001^{* *}$ \\
\hline total & 88 & $20.31 \pm 17.16$ & $74.91 \pm 15.4$ & $<0.001^{* *}$ \\
\hline & & & & \\
\hline
\end{tabular}

Independent sample $t$ test** statistically significant difference $(\mathbf{p}<0.01)$

Table 4:- Correlation between Mean Score of the children with JRA and healthy children reports regarding to quality of life Domains.

\begin{tabular}{|l|c|c|c|c|}
\hline & $\begin{array}{c}\text { Children with } \\
\text { JRA (n=100) }\end{array}$ & $\begin{array}{c}\text { Healthy } \\
\text { Children } \\
(\mathbf{n = 1 0 0})\end{array}$ & $\mathbf{r}$ & $\mathbf{P}$ \\
\hline Pain and Hurt & $3.9 \pm 3$ & $13.26 \pm 2.56$ & 0.85 & $<0.001^{* *}$ \\
\hline Daily Activities & $4.7 \pm 3.66$ & $17.51 \pm 3.33$ & 0.996 & $<0.001^{* *}$ \\
\hline Treatment & $7.48 \pm 5.78$ & $24.01 \pm 5$ & 0.997 & $<0.001^{* *}$ \\
\hline Worry & $2.76 \pm 2.42$ & $10.26 \pm 2.3$ & 0.992 & $<0.001^{* *}$ \\
\hline Communication & $3.07 \pm 2.51$ & $10.13 \pm 2.62$ & 0.980 & $<0.001^{* *}$ \\
\hline
\end{tabular}

** Statistically significant Correlation $(\mathbf{p}<0.01)$ 
Tanta Scientific Nursing Journal

Table (5):- Relation between quality of life levels and personal data of children

\begin{tabular}{|c|c|c|c|c|c|c|c|c|c|c|c|c|c|c|}
\hline & \multicolumn{6}{|c|}{ Children with JRA $(n=100)$} & \multirow{3}{*}{ P. value } & \multicolumn{6}{|c|}{ Healthy Children $(n=100)$} & \multirow{3}{*}{ P. value } \\
\hline & \multicolumn{2}{|c|}{$\begin{array}{c}\text { Poor } \\
(n=71)\end{array}$} & \multicolumn{2}{|c|}{$\begin{array}{c}\text { Faire } \\
(n=22)\end{array}$} & \multicolumn{2}{|c|}{$\begin{array}{l}\text { Good } \\
(n=7)\end{array}$} & & \multicolumn{2}{|c|}{$\begin{array}{l}\text { Poor } \\
(n=10)\end{array}$} & \multicolumn{2}{|c|}{$\begin{array}{l}\text { Faire } \\
(n=30)\end{array}$} & \multicolumn{2}{|c|}{$\begin{array}{c}\text { Good } \\
(n=60)\end{array}$} & \\
\hline & No & $\%$ & No & $\%$ & No & $\%$ & & No & $\%$ & No & $\%$ & No & $\%$ & \\
\hline Age & \multicolumn{2}{|c|}{$13.05 \pm 1.81$} & \multicolumn{2}{|c|}{$13.71 \pm 1.25$} & \multicolumn{2}{|c|}{$12.25 \pm 1.39$} & \multirow[t]{2}{*}{0.269} & \multirow[t]{2}{*}{$\mathbf{0}$} & \multirow[t]{2}{*}{$\mathbf{0}$} & \multicolumn{2}{|c|}{$15 \pm 0$} & \multicolumn{2}{|c|}{$13.12 \pm 1.39$} & $<0.001 * *$ \\
\hline \multicolumn{12}{|l|}{$\begin{array}{l}\text { Education } \\
\text { levels }\end{array}$} & & & \\
\hline $\begin{array}{l}\text { Non- } \\
\text { educated }\end{array}$ & 11 & 11 & 8 & 8 & $\mathbf{0}$ & $\mathbf{0}$ & \multirow{4}{*}{$0.036 *$} & $\mathbf{0}$ & $\mathbf{0}$ & 7 & 7 & 2 & 2 & \multirow{4}{*}{$0.002 * *$} \\
\hline Primary & 26 & 26 & 8 & 8 & 3 & 3 & & 6 & 6 & 4 & 4 & 17 & 17 & \\
\hline Preparatory & 19 & 19 & 4 & 4 & $\mathbf{0}$ & $\mathbf{0}$ & & $\mathbf{0}$ & $\mathbf{0}$ & 12 & 12 & 19 & 19 & \\
\hline Secondary & 15 & 15 & 2 & 2 & 4 & 4 & & 4 & 4 & 7 & 7 & 22 & 22 & \\
\hline \multicolumn{15}{|l|}{ Gender } \\
\hline Mail & 20 & 20 & 14 & 14 & $\mathbf{0}$ & $\mathbf{0}$ & \multirow{2}{*}{$0.001 * *$} & 5 & 5 & 11 & 11 & 18 & 18 & \multirow{2}{*}{0.435} \\
\hline Female & 51 & 51 & 8 & 8 & 7 & 7 & & 5 & 5 & 19 & 19 & 42 & 42 & \\
\hline \multicolumn{15}{|l|}{ Residence } \\
\hline Rural & 23 & 23 & 6 & 6 & 7 & 7 & \multirow{2}{*}{$0.001 * *$} & 2 & 2 & 17 & 17 & 35 & 35 & \multirow{2}{*}{0.074} \\
\hline Urban & 48 & 48 & 16 & 16 & 0 & $\mathbf{0}$ & & 8 & 8 & 13 & 13 & 25 & 25 & \\
\hline
\end{tabular}

* Statistically significant difference $(\mathbf{p}<0.05)$

** Highly statistically significant difference $\quad(p<0.01)$.

Table (6):- Correlation between Quality of life domains in the studied group

\begin{tabular}{|l|c|c|}
\hline Variables & R & P \\
\hline Pain and Hurt & 0.904 & $<0.001^{* *}$ \\
\hline Daily Activities & 0.929 & $<0.001^{* *}$ \\
\hline Treatment & 0.922 & $<0.001^{* *}$ \\
\hline Worry & 0.916 & $<0.001^{* *}$ \\
\hline Communication & 0.913 & $<0.001^{* *}$ \\
\hline
\end{tabular}

* Statistically significant Correlation $(\mathrm{p}<0.01)$

Vol.14 No.1 May, 2018 


\section{Tanta Scientific Nursing Journal}

\section{Discussion:}

Juvenile Idiopathic Arthritis (JIA) is the maximum common chronic rheumatic disease in childhood, with a frequency assessed between 10 and 20 cases/children/year ${ }^{(5)}$. When it's categorized by a chronic course, requiring long-term therapy and intense follow-up, JIA can have a major influence on children's life. Mothers as well have to cope with the diagnosis of a chronic disease, and the management of the effects that such a diagnosis can have on their children's everyday life, with a possible impact on the mothers-to-child relationship. ${ }^{(15)}$

Recently the quality of life is known as a vital consequence variable in children with chronic illness. The QoL drives afar the diminishing/disability and handicap range by requesting what children' health condition inhibits them from achievement, also their emotional reaction to these limitations. It also reflects the influences of the personal social and economic resources that an individual has and the way in which these interact with health status. Therefore. QoL could be defined as perception of people about life, values, goals, standard, and interests (16)

The results of the present study revealed that the majority of children with juvenile rheumatoid arthritis (JRA) have poor level of quality of life, while only little percentage of healthy children have poor level. These results can be explained that there are adverse effect of the disease on the children' quality of life, most of children and their mothers during the interview of data collection mentioned that many normal activities of daily living such as walking, combing hair, wearing clothes, showering, even eating are affected by the disease, also, some of studied children leave their school. These results answer the suggested study question. So, full attention must be paid to the patient, understanding the nature and mechanism of the disease and the means of treatment. It has been proven that giving the child love and affection by mothers or others plays a key role for effective treatment. As adult rheumatism affects children as early as their first years. Therefore, the mother must pay attention to some of the symptoms that the child complains, such as joint pain, bloating, morning stiffness and high temperature.

These results were agree with, GutiérrezSuárezet al. ${ }^{(11)}$, who observe the health related quality of life of children with juvenile rheumatoid arthritis live in 3 diverse locations, they reported that children with juvenile rheumatoid arthritis have been 


\section{Tanta Scientific Nursing Journal}

described to have a poorer health-related quality of life than healthy children, also, they observed that arthritis pediatric patients in the 14-16 year age group presented lower back forte, ratio of body fat, and performance abilities than health one.

Also, Shaw et al. ${ }^{(17)}$ who supported the result of current study for health related quality of life among adolescents with juvenile rheumatoid arthritis and showed that the children with juvenile rheumatoid arthritis have been stated to have a minor health-related quality of life than normal. 17 year-old juveniles with rheumatoid arthritis were establishing to have the poorest functional abilities.

The present study results are similar to those stated by Varniet $\boldsymbol{a l}^{(\mathbf{1 2})}$ who create and appraise the PedsQL in pediatric rheumatology: reliability, validity, and sensitivity of the Pediatric Quality of Life Inventory Generic Core Scales and Rheumatology Module. Besides, children with juvenile rheumatoid arthritis in both studies described significantly lesser degree on all the PedsQL scales than those described by the 'healthy subject' in the study of Varniet al. The current results were in line with Hyo-Jeong et al. (18) who studies the correlation between functional capability and health-related quality of life of children with juvenile rheumatoid arthritis; they establish that children with juvenile rheumatoid arthritis have been stated to have an inferior health-related quality of life than healthy children. The mean scores for the majority of diseased children, and their mothers' reports in the present study were low regarding the dealing with pain \& hurt, daily activities, treatment, worry and communication items. These could be related to the children's unsatisfactory response to disease process and its management.

The current study illustrated that reports from the children with JRA also highlighted the difficulty they have communicating about their problems with health professionals. This is an important issue as good quality communication between children and clinicians is an essential prerequisite to the provision of effective help for children with problems in these areas.

The results of the present study was agreed with Amine et al. ${ }^{(19)}$ who conduct a health related quality of life investigation about children and adolescents with juvenile rheumatoid arthritis and mentioned that the arthritis children in the age group 14-16 year presented physical functional skills lower than health one, also, health-related 


\section{Tanta Scientific Nursing Journal}

quality of life reduced in the adolescent period and worsened with a later diagnosis.

The current study were in-agreement with Sandstedtet al. ${ }^{(10)}$ who assess muscle strength, physical abilities and well-being in children and adolescents with JIR and the effect of an exercise program, they cited that the early stage of juvenile rheumatoid arthritis, pain leads mothers, school staff, and medical experts to aggressively limit children's exercise for their protection. Out of the fear of damaging weak joints, children's participation in normal childhood activities tends to be limited, and patients take greater precautions when outdoors.

These findings are also supported by many authors where they stated that the mean score for children's reports concerning the communication items were generally low and children's compliance in receiving their medications will eliminate the infection and inflammation of joints pain reflected on achieving a good health ${ }^{(\mathbf{2 0})}$.

Moorthy, et al. ${ }^{(21)}$ who determined that the decrease in physical movement from the ages of 8 through 16, a key period for normal development, delays the optimization of large-scale movements that require speed, power, and coordination. As childhood development takings through the collaboration of physical, emotional, social, and school scopes, inadequate development would eventually have an influence on health-related quality of life. An early decrease in physical activity because of pain will next affect physical power and the quality of life of children with juvenile rheumatoid arthritis, and result in additional reduce in physical abilities making a dangerous cycle.

\section{Present study was concluded that the} majority of children with juvenile rheumatoid arthritishad a low quality of life compared to health children in all domains. Reports of children established similar results with significant positive correlations between children reports in the majority of the studied elements of quality of life about juvenile rheumatoid arthritis. The present study reports from children also mentioned that they may have difficulty communicating with others about their illness due to pain.

The study was recommended that health promotion education program for children with juvenile rheumatoid arthritis, and their family members are important. Nurses, physicians, mothers and teachers must be informed of the risk for impaired healthrelated quality of life among juvenile 
rheumatoid arthritis children to promote interventions that must improve health outcomes.

\section{References:}

\section{1-Hoffart C, Sherry $\quad$ D. "Early} identification of juvenile idiopathic arthritis". Journal of Musculoskeletal Medicine. 2010;247 (2).

2-Takken T, van der Net J, Helders P. Do juvenile idiopathic arthritis patients benefit from an education program? A pilot study. Arthritis Rheum2009;45(1):81-5.

3-Duffy C, Watanabe Duffy K, Gibbon M, Yang $\mathrm{H}$, Platt R. Accuracy of functional outcome measures in defining improvement in juvenile idiopathic arthritis. Ann Rheum Dis2011;59:724

4- Norrby U, Nordholm $L$ and Andersson-Gäre $\quad$ B .Health-related quality of life in children diagnosed with asthma, diabetes, juvenile chronic arthritis or short stature. ActaPaediatr, 2014; 95: 450-456. [PubMed]

\section{5-Feldman D, De Civita M, Dobkin P,} Malleson P, Meshefedjian G, Duffy C. Effects of adherence to treatment on short term outcomes in children with juvenile idiopathic arthritis. Arthritis Rheum; 2010;57:905-12.

6-McDonagh J, Southwood T, Shaw K. The impact of a coordinated transitional care programme on adolescents with juvenile idiopathic arthritis. Rheumatology (Oxford)2015;46:161-8.

7-Hays R., Vickrey B., Hermann B., Perrine K., Cramer J. and Meador K. Agreement between self-reports and proxy reports of quality of life in juvenile idiopathic arthritis children. Qual Life Res2011; 19(4):159-168.

8-Eiser $\mathbf{C} \&$ Morse $\mathbf{R}$.A review of measures of quality of life for children with juvenile idiopathic arthritis. Arch Dis Child2008; 84:205-211.

9-Ravens-Sieberer U, Erhart M, Wille N, Wetzel R, Nickel J, Bullinger $M$. Generic health-related quality of life assessment in children and adolescents: methodological considerations. Pharmaco economics, 2009;24(2):1199-1220.

10-Sandstedt E, Fasth A and Eek M . Muscle strength, physical fitness and well-being in children and adolescents with juvenile idiopathic arthritis and the effect of an exercise programme: a randomized controlled trial. Pediatr Rheumatol Online J, 2013; 11(1): 7..

\section{1-Gutiérrez-Suárez R, Pistorio $A$ and} Cespedes A .Health-related quality of life of patients with juvenile idiopathic arthritis coming from 3 different geographic areas. The Pediatric Rheumatology International Trials Organisation (PRINTO) multinational 
quality of life cohort study. Rheumatology (Oxford)2014; 46: 314-320.

12-Varni J, Seid M, Smith Knight T, Burwinkle T, Brown J, Szer I..The PedsQL $^{\mathrm{TM}}$ in pediatric rheumatology: reliability, validity, and responsiveness of the Pediatric Quality of Life Inventory ${ }^{\mathrm{TM}}$ Generic Core Scales and Rheumatology Module. Arthritis \& Rheumatism.;2002;46(3):714-725. [Pub Med]http://www.pedsql.org/pedsql3.html

13-James W. and Varni . Scaling And Scoring of The Pediatric Quality of Life Inventory ${ }^{\mathrm{TM}}$ PedsQL. PedsQL TM 3.0 Rheumatology Module, CHILD and PARENT reports for Children (ages 812) and Teens (ages 13-18). Version 14.College of Architecture and College Station, Texas2014; 77843-3137 USA. $117-121$.

\section{4-De Benedetti F, Meazza C, Vivarelli}

M. "Functional and systemic-onset juvenile idiopathic arthritis treatment". Arthritis Rheum.2013 ; 48 (5): $\quad$ 1398-407. doi:10.1002/art. 10882. PMID 12746913.

\section{5-Noll C, Ferraz M, Goldenberg} J.Pediatric Escola Paulista de Medicina Range of Motion Scale: a reduced joint count scale for general use in juvenile rheumatoid arthritis. J Rheumatol 2009;26 (1):909-13.
16-Yaghoubi H, Scarisbrick P, England R, Smythe H .Musculosketal symptoms and non-REM sleep disturbance in patients with "fibrositis syndrome" and healthy subjects. Psychosom Med2009;37 (2):341-51.

17-Shaw K, Southwood $T$ and Duffy C.Health-related quality of life in adolescents with juvenile idiopathic arthritis. Arthritis Rheum2012; 55 (1): 199-207.

18-Hyo-Jeong K., You Lim K. and Suk M. Relation between functional ability and health-related quality of life of children with juvenile rheumatoid arthritis J PhysTher Sci 2015.; 27(3): 837-840.

\section{9-Amine B, Rostom $S$ and Benbouazza}

K. Health related quality of life survey about children and adolescents with juvenile idiopathic arthritis. RheumatolInt, 2009; 29: 275-279.

20-Zamir G, Press J, Tal A, Tarasiuk A. Sleep fragmentation in children with juvenile rheumatoid arthritis. J Rheumato 2013;1;25:1191-7.

\section{1-MoorthyP, Nahir M, Lorber M, Scharf} Y .Non-steroidal anti-inflammatory drug therapy in rheumatoid arthritis patients. Lack of association between clinical improvement and effects on sleep. Arthritis Rheum 2008;34:655-9. 